\title{
The Bacterial Phytoene Desaturase-Encoding Gene (CRTI) is an Efficient Selectable Marker for the Genetic Transformation of Eukaryotic Microalgae
}

\author{
Ana Molina-Márquez ${ }^{1}$, Marta Vila ${ }^{1,2}$, Javier Vigara ${ }^{1}$, , Ana Borrero ${ }^{1}$ and Rosa León ${ }^{1, *}$ \\ 1 Laboratory of Biochemistry, Faculty of Experimental Sciences, Marine International Campus of \\ Excellence (CEIMAR), University of Huelva, 2110 Huelva, Spain; ana.molina@dqcm.uhu.es (A.M.-M.); \\ mvila@phycogenetics.com (M.V.); vigara@uhu.es (J.V.); anika_b92@hotmail.com (A.B.) \\ 2 PhycoGenetics SL, C/Joan Miró Nº, Aljaraque, 21110 Huelva, Spain \\ * Correspondence: rleon@uhu.es; Tel.: +34-959219951
}

Received: 7 February 2019; Accepted: 5 March 2019; Published: 12 March 2019

\begin{abstract}
Genetic manipulation shows great promise to further boost the productivity of microalgae-based compounds. However, selection of microalgal transformants depends mainly on the use of antibiotics, which have raised concerns about their potential impacts on human health and the environment. We propose the use of a synthetic phytoene desaturase-encoding gene (CRTIop) as a selectable marker and the bleaching herbicide norflurazon as a selective agent for the genetic transformation of microalgae. Bacterial phytoene desaturase (CRTI), which, unlike plant and algae phytoene desaturase (PDS), is not sensitive to norflurazon, catalyzes the conversion of the colorless carotenoid phytoene into lycopene. Although the expression of CRTI has been described to increase the carotenoid content in plant cells, its use as a selectable marker has never been testedin algae or in plants. In this study, a version of the CRTI gene adapted to the codon usage of Chlamydomonas has been synthesized, and its suitability to be used as selectable marker has been shown. The microalgae were transformed by the glass bead agitation method and selected in the presence of norflurazon. Average transformation efficiencies of 550 colonies $\mu \mathrm{g}^{-1}$ DNA were obtained. All the transformants tested had incorporated the CRTIop gene in their genomes and were able to synthesize colored carotenoids.
\end{abstract}

Keywords: microalgae; Chlamydomonas reinhardtii; genetic transformation; carotenoid; CRTI; phytoene desaturase

\section{Introduction}

Microalgae have attracted considerable interest for the production of a wide range of compounds of applied interest due to their easy growth, their ability to fix atmospheric $\mathrm{CO}_{2}$, and the valuable metabolites that some species can produce, which include pigments, food supplements, vitamins, antioxidants, polysaccharides, lipids, and other bioactive products [1-3]. Moreover, in the last years, there has been an increasing interest in microalgae as a potential source of biofuels [4,5]. However, despite the expectations generated, the production of biofuels and other useful compounds from microalgae will not be economically feasible unless the cost of microalgae cultivation and harvesting is lowered and the productivity increased. Genetic manipulation and synthetic biology show great promise to further boost the productivity of microalgae-based compounds [6-9]. Significant advances have been achieved in the development of molecular tools for genetic manipulation of microalgae. However, important challenges remain. One important issue is the fact that the selection of microalgal transformants depends mainly on the use of antibiotics as selective agents [10]. Antibiotic resistance genes continue to be the most commonly used selectable markers for the genetic manipulation of 
algae and plants. However, the risk of horizontal gene transfer has raised concerns about their potential impacts on human health and the environment, and has encouraged the search for new non-antibiotic-based selection procedures [11].

Herbicide resistance genes are a good alternative for the selection of genetically modified plant cells. Examples of this are the glyphosate aminotransferase [12] or the acetolacetate synthase genes [13], which confer resistance to glyphosate and sulfomturon methyl herbicides, respectively, and have been used as reporter genes in the transformation of the unicellular chlorophyte Chlamydomonas reinhardtii and other microalgae, such as Porphyridium sp. [14] or Parietochloris incisa [15]. An interesting herbicide-based selective strategy is the use of mutated versions of the phytoene desaturase gene (PDS) resistant to bleaching herbicides such as norflurazon $[16,17]$. Phytoene desaturase (PDS) catalyzes the conversion of the colorless phytoene into $\zeta$-carotene, which is converted to lycopene by $\zeta$-carotene desaturase (ZDS) and carotene isomerase (CRTISO). PDS is a membrane-associated protein that uses the flavin adenine dinucleotide (FAD) as a redox cofactor, through which electrons are transferred to the plastoquinone, thereby connecting the desaturation of carotenoids with the photosynthetic electronic transport chain [1]. Treatment with norflurazon causes inhibition of phytoene desaturase by competition with its cofactors, resulting in suppression of carotenoid synthesis and cellular whitening [18]. By modifying key amino acids in the FAD binding domain, some authors have obtained mutated norflurazon-resistant versions of PDS and setup genetic selective procedures based on norflurazon as a selective agent $[17,19]$.

In bacteria and fungi, however, the three reactions that convert phytoene into lycopene are carried out by a single enzyme, bacterial phytoene desaturase (CRTI), which presents a low degree of homology with the corresponding plant phytoene desaturase [20]. The CRTI gene seems to have emerged independently in evolution and, unlike plant and algae PDS, is not sensitive to norflurazon [21]. The CRTI gene was first identified and functionally analyzed by Misawa and coworkers [22] from the soil bacteria Erwinia uredovora, currently renamed as Pantotea ananatis. The pioneering work of Sandman's group showed that expression of this bacterial CRTI gene in tobacco plants enhanced the production of $\beta$-carotene. Furthermore, they observed higher resistance to the herbicide norflurazon in transgenic CRTI-expressing plants [23]. Several subsequent studies reported the expression of the bacterial carotenoid gene cluster from Pantotea, including the CRTI gene, to increase the carotenoid content in higher plants such as rice [24], tomato [25], or potato [26]. However, the possible use of CRTI as a selectable marker gene has never been investigated in algae or in plants. Poor expression of bacterial CRTI in microalgae, beside potential silencing and lack of stability of the transgene in algae, has withdrawn its use as a selectable marker. In the present study, we have synthesized a codon-adapted version of the bacterial CRTI gene and showed its suitability to be used as selectable marker gene in the genetic transformation of the model microalga Chlamydomonas reinhardtii.

\section{Results and Discussion}

\subsection{Construction of Plasmid pSIO6PLK-CRTIop}

A synthetic CRTI gene with the codon usage adapted to $C$. reinhardtii was designed and synthesized by Genescript Co (Piscataway, NJ, USA). The mean difference between codon usage of the wild type CRTI gene and the genome of $C$. reinhardtii was $24 \%$, as calculated using the graphical codon usage analyser v. 2.0 (http://gcua.schoedl.de/index.html). This difference was reduced to only $13 \%$ for the synthetic codon-optimized version. The CRTIop gene was fused to a DNA fragment which encoded the chloroplast transit peptide of the RuBisCo small subunit, and this tpCRTIop fusion product was cloned between the BstBI/ BamHI restriction sites of the p106PLK plasmid, described in Section 3.2, generating the expression cassette outlined in Figure 1. 


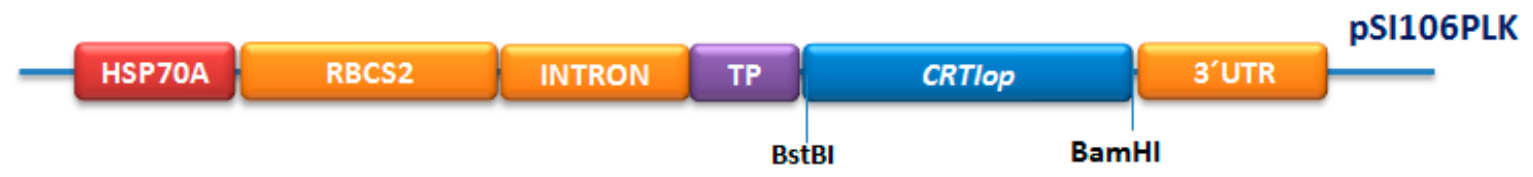

Figure 1. Expression cassette of the pSI106PLK-tpCRTIop plasmid.Abbreviations: HSP70A, heat shock protein 70A promoter; RBCS2, ribulose 1,5-biphosphate carboxylase small subunit promoter; TP, chloroplastic transit peptide; CRTIop, codon-optimized bacterial phytoene desaturase; $3^{\prime}$ UTR terRBCS2, ribulose 1,5-biphosphate carboxylase small subunit terminator region.

\subsection{Sensitivity of the Chlorophyte Microalgae to the Bleaching Herbicide Norflurazon}

The ability of CRTI to act as a selectable marker for microalgae transformation is based on the sensitivity of the target microalgae to herbicides which inhibit phytoene desaturase (PDS). We have tested the sensitivity of the model chlorophyte Chlamydomonas reinhardtii to the bleaching herbicide norflurazon by culturing it with growing concentrations of the herbicide and determining the lethal doses (Figure 2). Samples of control non-transformed C. reinhardtii cultures were harvested at the exponential phase of growth and 100-fold concentrated by centrifugation, and $10 \mu \mathrm{L}$ drops of the concentrated suspension were spotted on multi-well plates with growing concentrations $\left(0-25 \mu \mathrm{g} \mathrm{mL}^{-1}\right)$ of the herbicide norflurazon. Concentration of the culture was done to mimic the conditions in which the transformation experiments are done (see Section 3.3). The minimal inhibitory norflurazon concentration for $C$. reinhardtii was $1.5 \mu \mathrm{g} \mathrm{mL}^{-1}$ after 15 days of incubation in the presence of norflurazon, as can be observed in Figure 2B. It is interesting to note that at shorter times, herbicide concentrations as low as $0.5 \mu \mathrm{g} \mathrm{mL}^{-1}$ seemed to inhibit $C$. reinhardtii growth. However, the microalgaeare able to survive and grow after an adaptation period. To establish the real lethal dose and avoid false negatives, in the subsequent transformation experiments it is necessary to follow the inhibitory effect of norflurazon for a long time period. All C. reinardtii transformants were selected at norflurazon concentrations $\geq 1.5 \mu \mathrm{g} \mathrm{mL} \mathrm{m}^{-1}$.

A: 4 days after incoulation

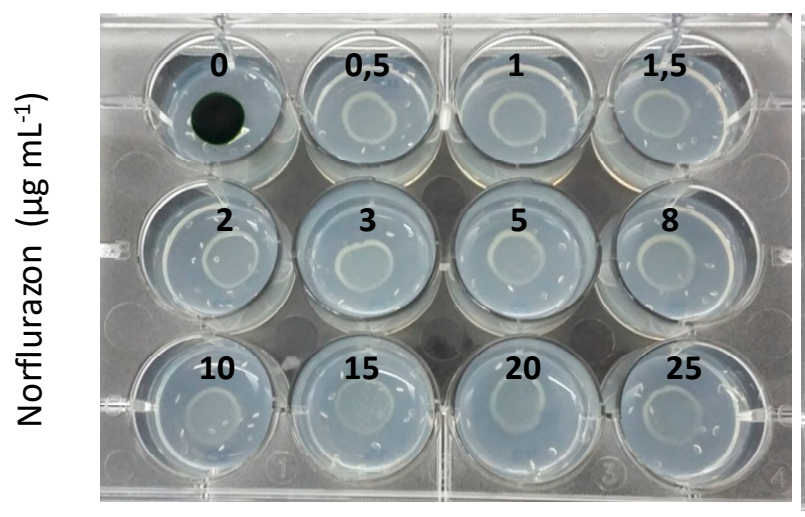

B: 15 days after inoculation

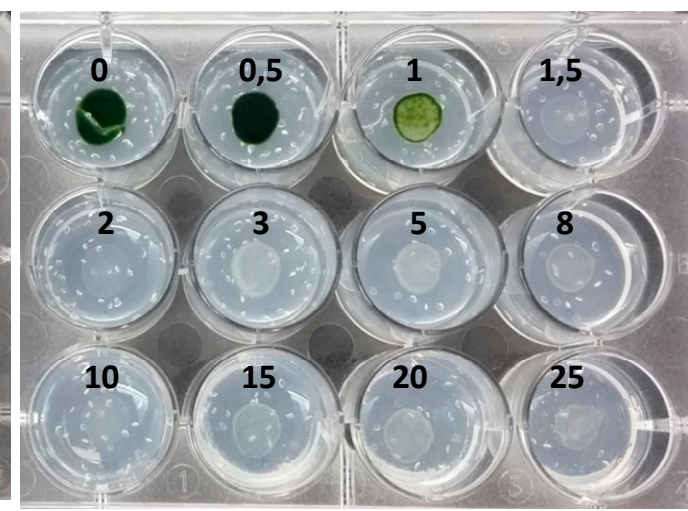

Figure 2. Norflurazon sensitivity test for the clorophyceae microalga Chlamydomonas reinhardtii. Drops $(10 \mu \mathrm{L})$ of a 100-fold concentrated C. reinhardtii control untransformed culture were spotted on agar-solidified Tris-acetate phosphate (TAP) culture medium with increasing concentrations of the bleaching herbicide norflurazon, and their growth was evaluated 4 (A) and 15 (B) days after inoculation.

Furthermore, sensitivity experiments were carried out for other microalgal species, such as the freshwater trebouxiophyceae Chlorella sorokiniana, the marine prasinophyceae Tetraselmis suecica, and the halophilic chlorophyceae Dunaliella salina and Dunaliella bardawill. These studies revealed that the inhibitory norflurazon concentration dose was between 0.5 and $2 \mu \mathrm{g} \mathrm{mL}{ }^{-1}$ for all the tested species, and that norflurazon can be an adequate selective agent for many different microalgal species, 
including marine microalgae, for which traditional selective antibiotic agents are usually inefficient due to interference with the saline concentration of the medium (Figure S1).

\subsection{Transformation of Chlamydomonas reinhardtii with the Plasmid pSI106PLK-tpCRTIop and Selection of Norflurazon-Resistant Norf ${ }^{R}$-Chlamydomonas Transformants}

Chlamydomonas reinhardtii cells were transformed by the glass beads agitation method with the plasmid pSI106PLK-tpCRTIop and selected in Tris-acetate phosphate (TAP) medium with norflurazon $\left(1.5 \mu \mathrm{g} \mathrm{mL}^{-1}\right)$. Transformation efficiencies of 550 colonies $\mu \mathrm{g}^{-1}$ DNA were obtained (Figure 3A). This transformation efficiency is of the same order as that usually obtained for transformations with paromomycin as the selective agent [27]. A randomly selected group of the obtained transformants were cultured in $2 \mathrm{~mL}$ of liquid TAP medium with norflurazon for $48 \mathrm{~h}$, and their cellular density was then adjusted to the same value. Drops of each transformed culture were spotted on TAP agar plates with a higher concentration of norflurazon $\left(4 \mu \mathrm{g} \mathrm{mL}{ }^{-1}\right)$, and those which grew at this concentration of the herbicide were further checked by PCR using the specific primers CRTIopFor (CAGCCGCGCCGTGTTCAAAGAG) and CRTIpoRev (CAGCAGGTCGCGGTAGGTGTG), as illustrated in Figure 3B. It is necessary to consider that nuclear transformations of microalgae take place by heterologous recombination. This means that the CRTIop gene is randomly inserted into the algal genome, and its expression level and stability largely depend on the insertion point. The two-round selection strategy with increasing concentrations of norflurazon allows the selection of the transformants with the highest resistance to the herbicide. Insertion of the CRTIop into the C. reinhardtii nuclear genome was confirmed in all the transformants checked (Figure 3C).

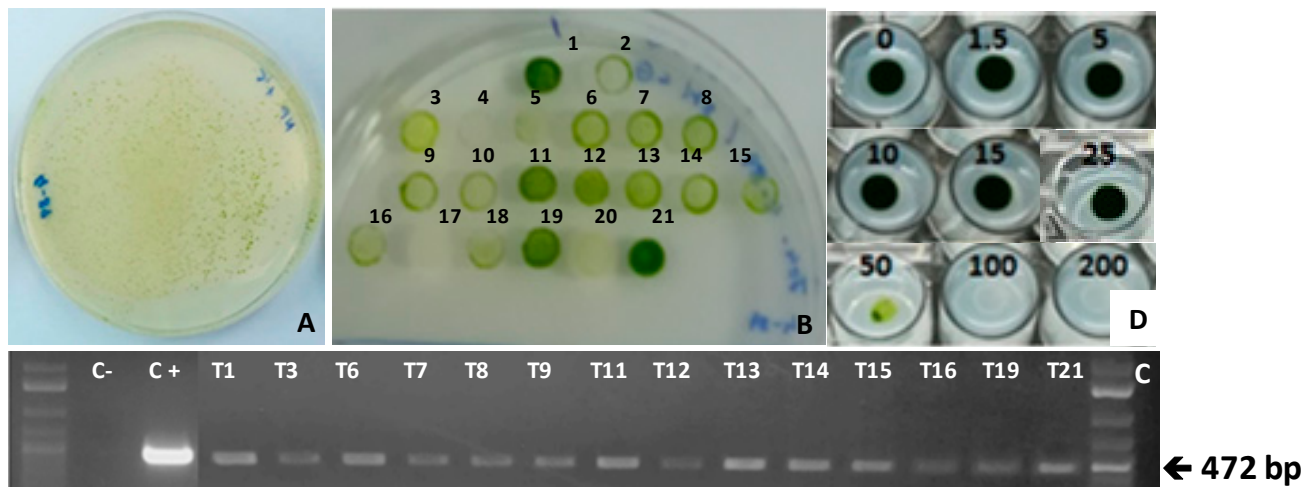

Figure 3. Molecular and phenotypic analysis of $\mathrm{Norf}^{\mathrm{R}}$-Chlamydomonas transformants. Chlamydomonas transformants selected in TAP with $1.5 \mu \mathrm{g} \mathrm{mL}^{-1}$ of norflurazon (A) were cultured in TAP agar plates with $4 \mu \mathrm{g} \mathrm{mL}^{-1}$ of norflurazon for 10 days (B). A band of the expected size (472 bp) corresponding to the CRTIop amplicon was shown in all the transformants tested (C). A norflurazon sensitivity test for the selected transformant T21 (D) was carried out as described in the Figure 2 legend with the indicated concentrations of norflurazon (from 0 to $200 \mu \mathrm{g} \mathrm{mL}^{-1}$ ).

The transformants which grew more vigorously were subjected to a norflurazon sensitivity test as described in Figure 1. C. reinhardtii transformed with CRTIop showed a 33-fold increase in their tolerance to norflurazon, with an inhibitory dose of $50 \mu \mathrm{g} \mathrm{mL}^{-1}$, equivalent to $160 \mu \mathrm{M}$, as shown for transformant T21 (Figure 3D) and for the other $\operatorname{Norf}^{\mathrm{R}}$-transformants selected (Figure S2). The synthetic tpCRTIop gene allowed for norflurazon-based selection of transformants with no background of spontaneous herbicide-resistant clones. The level of resistance to norflurazon acquired by the $C$. reinhardtii transformed with CRTIop is of the same order as the resistance reported by Suarez et al. [28] or Bruggeman and coworkers [12], who found 30- and 40-fold increases, respectively, in the tolerance to norflurazon for transgenic Chlamydomonas harbouring modified versions of its own PDS gene. Similar strategies using mutated PDS versions and norflurazon have been successfully 
used for the selection of other transformed microalgae species, such as Haematococcuspluvialis [29,30], Chlorella zofingiensis [31,32], or Isocrhrysis [33].

\subsection{Carotenoid Composition of Norflurazon-Resistant Norf ${ }^{R}$-Chlamydomonas Transformants}

The phenotypic characteristics of the selected transformants were further studied by chromatographic analysis. First, we compared the phytoene contents in the Norf ${ }^{\mathrm{R}}$-transformants with that of the control cells grown in the presence and in the absence of norflurazon (Table 1). As expected, in C. reinhardtii cultures grown without the herbicide, only trace levels of phytoene were found. After $24 \mathrm{~h}$ of growth in the presence of norflurazon $\left(1.5 \mu \mathrm{g} \mathrm{mL}^{-1}\right)$, the phytoene contents in control untransformed cells reached $4.4 \mathrm{mg} \mathrm{g}^{-1} \mathrm{DW}$. However, the phytoene intracellular concentrations of Norf ${ }^{\mathrm{R}}$-transformants grown with and without norflurazon ranged between $1.5 \mathrm{mg} \mathrm{g}^{-1} \mathrm{DW}$, for transformant $\mathrm{T} 21$, to $2.1 \mathrm{mg} \mathrm{g}^{-1} \mathrm{DW}$, for transformant $\mathrm{T} 11$. This is far from the intracellular level of phytoene in the control, which is between two and three times higher. This shows that the CRTIop gene is correctly expressed in the transformed microalgae and is able to convert phytoene into the downstream carotenoids. However, the presence of certain contents of phytoene in all the transformants tested indicates that the foreign CRTI is less efficient than the endogenous PDS in the absence of the herbicide.

Table 1. Concentration of the colorless carotenoid phytoene in control cells (C2) and Norf $^{\mathrm{R}}$-transformants $(\mathrm{T})$, grown for $24 \mathrm{~h}$ with norflurazon. Control cells non-treated with norflurazon (C1) have also been included as a reference. Values are the average of three biological replications. Standard deviation is indicated.

\begin{tabular}{ccccccc}
\hline Strain & C1 & C2 & T1 & T11 & T19 & T21 \\
\hline Norflurazon $\left(\mu \mathrm{g} \mathrm{mL}^{-1}\right)$ & - & 1.5 & 1.5 & 1.5 & 1.5 & 1.5 \\
Phytoene $\left(\mu \mathrm{gL} \mathrm{m}^{-1}\right)$ & $0.1 \pm 0.5$ & $4.4 \pm 0.4$ & $1.8 \pm 0.1$ & $2.1 \pm 0.2$ & $2 \pm 0.2$ & $1.5 \pm 0.1$ \\
\hline
\end{tabular}

A representative $\operatorname{Norf}^{\mathrm{R}}$-transformant $(\mathrm{T} 21)$ and the control untransformed strain were grown in TAP medium with norflurazon $\left(1.5 \mu \mathrm{g} \mathrm{mL}{ }^{-1}\right)$ for a complete analysis of their carotenoid profiles along the time. Samples were withdrawn every $24 \mathrm{~h}$, and pigments were extracted and analyzed (Figure 4). Typical chromatograms of the pigment extracts from Control (C2) and Norf ${ }^{\mathrm{R}}$-transformant cells registered at 288 and $450 \mathrm{~nm}$, and are shown in the Supplementary Material (Figure S3).

In control parental Chlamydomonas treated with norflurazon, there was a reduction of all the colored carotenoids, excepting zeaxanthin, and an important accumulation of phytoene, due to the inhibitory effect of norflurazon. By contrast, in transformant cells treated with norflurazon, the reduction of the colored carotenoids and the accumulation of phytoene was much lower. After $24 \mathrm{~h}$ of incubation with norflurazon, the content of lutein in the Norf ${ }^{\mathrm{R}}$-transfomant was $50 \%$ higher than in the controls, while the content in $\beta$-carotene and violaxanthin was 2.5 times the level of control untransformed cells. These differences were even more acute for longer periods of incubation with norflurazon. The level of phytoene, on the contrary, was between three and five times higher in the norflurazon-treated control cells, reaching intracelullar levels of $4.4 \mathrm{mg} \mathrm{g}^{-1} \mathrm{DW}$ at $24 \mathrm{~h}$ and $6.7 \mathrm{mg} \mathrm{g}^{-1} \mathrm{DW}$ at $48 \mathrm{~h}$. This confirms that the CRTIop gene was working in the transformant, allowing the conversion of phytoene into lycopene and the subsequent carotenoids in the presence of norflurazon, which inhibits the endogenous PDS. Zeaxanthin was the only colored carotenoid which increased in the control untransformed cells, indicating a higher level of fotooxidative stress in these cells. This induces the xantophyll cycle, which catalyzes the conversion of violaxanthin into zeaxanthin. In the $\operatorname{Norf}^{\mathrm{R}}$-transfomants, the levels of zeaxanthin were inappreciable during the first $48 \mathrm{~h}$. Only after $72 \mathrm{~h}$ of growth, when cultures started to be nutrient-limited, there was certain synthesis of this xanthophyll. 

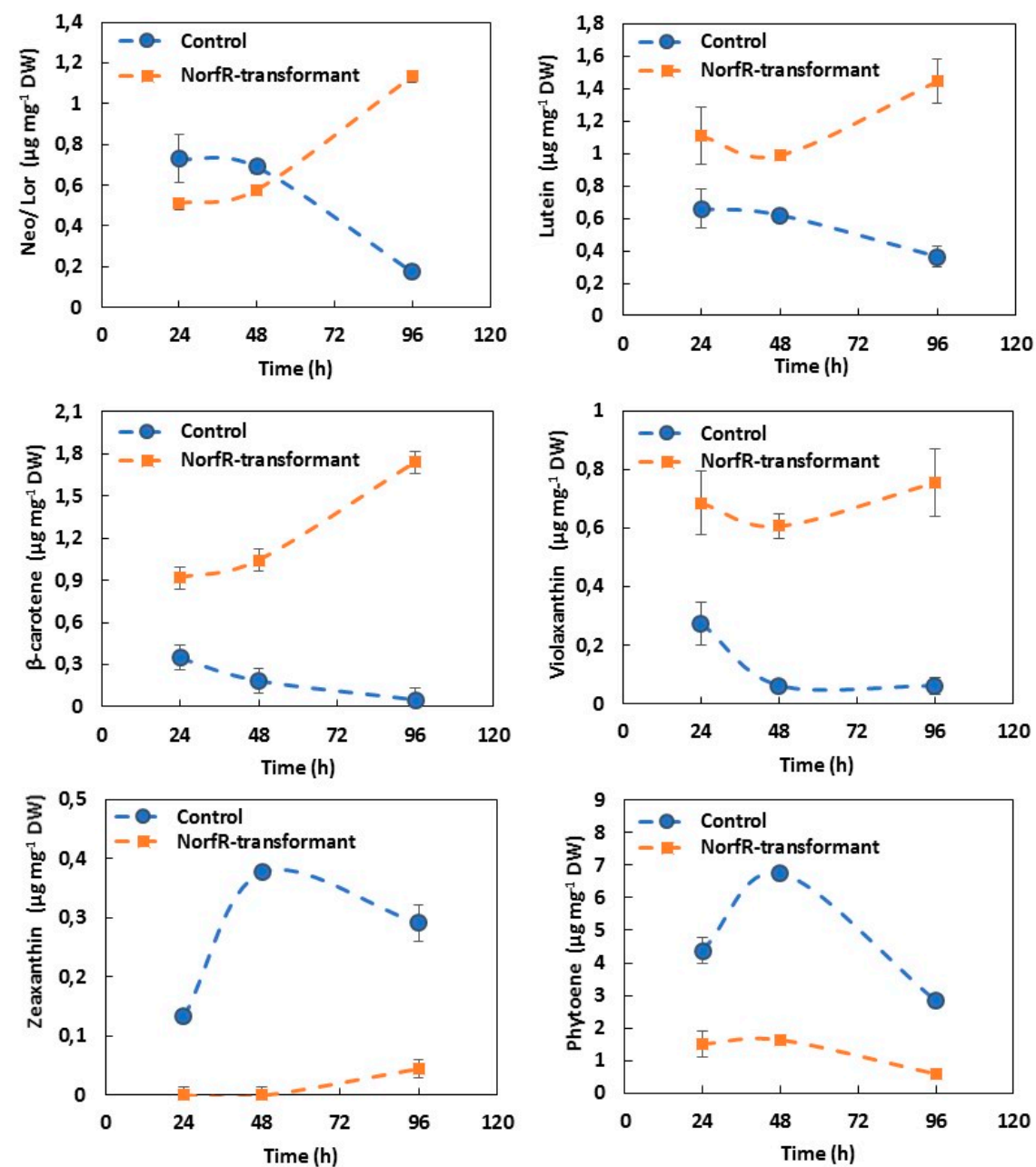

Figure 4. Time-course evolution of the main carotenoid pigments in C. reinhardtii control (๑) and

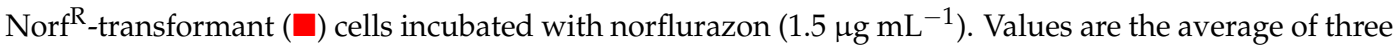
biological replicates and bars indicate standard deviation. Neoxanthin and Loroxanthin (Neo/Lor) are expressed as unique values since they are not resolved in the analytical conditions used.

In the presence of norflurazon, the growth of the parental strain was severely affected. Meanwhile, the growth rate of the Norf ${ }^{\mathrm{R}}$-transformantswas similar with and without norflurazon, and was slightly higher than the growth rate of the control wild type without herbicide (Figure S4A,B). The carotenoid content of the Norf ${ }^{\mathrm{R}}$-transformants grown without herbicide was also checked and resulted to be very similar to that of control cells (Figure S4C,D). This means that the transformants selected in the presence of norflurazon with CRTI as a marker gene can grow at a normal rate and have practically normal contents of carotenoids $[19,20]$. It could be expected that the expression of an exogenous phytoene desaturase caused an increase in the contents of carotenoids. The fact that the CRTIop transformants studied had intracellular levels similar to that of the control cells in the absence of norflurazon could be due to a limitation in the supply of precursors from the previous step catalyzed by the Phytoene synthase (PSY). However, further studies should be done to confirm this issue.

PDS is the second step in carotenoid biosynthesis and an important regulatory point of the pathway $[19,20]$. The inhibitory effect of norflurazon is well known and has been widely used to study the physiological consequences resulting from the lack of carotenoids in higher plants and microalgae [34]. We have corroborated that blocking PDS activity by chemical inhibition with norflurazon impedes the formation of downstream carotenoids in Chlamydomonas (Figure 4), which is in agreement with what Nigoyi's group observed by mutagenesis-induced PDS inactivation [34]. Furthermore, we demonstrated that the expression of the foreign CRTIop, which is not affected by the 
herbicide, allows bypass, at least partially, of the norflurazon-blocked step and enables the synthesis of colored carotenoids. Similar conclusions were reported by Liu and coworkers [35] or Steinbrenner and Sandmann [29], who used a modified PDS gene as a selectable marker for the genetic transformation of Chlorella zofingiensis and as H. pluvialis, respectively, and found that the transformants had the same or even higher carotenoid content than the untransformed controls.

\section{Materials and Methods}

\subsection{Strains and Culture Conditions}

Chlamydomonas reinhardtii 704 strain $(\mathrm{Cw} 15, \mathrm{Arg} 7, \mathrm{mt}+)$ was kindly donated by Dr. R. Loppes and cultured photomixotrophically in liquid or agar-solidified Tris-acetate phosphate (TAP) medium [36]. Tetraselmissuecica, kindly provided by IFAPA-Aguas del Pino station (Huelva, Spain), was cultured in $\mathrm{F} / 2$ medium in filtered sea water at $\mathrm{pH} 8$, as reported by Guillard and Ryther [37]. Dunaliella salina (CCAP 19/18) was obtained from the culture collection of algae and protozoa (Scotland, UK) and grown in the culture medium described by Johnson and coworkers [38]. All were grown in a culture chamber at $25^{\circ} \mathrm{C}$ under continuous white light irradiation $\left(50 \mu \mathrm{E} \mathrm{m}^{-2} \mathrm{~s}^{-1} \mathrm{PAR}\right)$.

\subsection{Microalgal Expression of pSI106PLK Plasmid}

Plasmid pSI106PLK is a renewed version of plasmid pSI104PLK [39]. It contains an expression cassette in which a multiple cloning site is preceded by the strong chimeric fusion promoter HSP70A:RBCS2, designed by Sizova [40], and the first intron of the RBCS2 gene, and is terminated by the $3^{\prime}$ untranslated region of RBCS2 (Figure 1).

\subsection{Chlamydomonas Nuclear Transformation}

Nuclear transformation of $C$. reinhardtii was carried out using the glass beads method [41] with minor modifications. Chlamydomonas cultures were grown as described in Section 3.1. to a cell density of $5 \times 10^{6}$ cells mL ${ }^{-1}$, and resuspended to get a 100-fold concentrated cell suspension. $0.3 \mathrm{~g}$ of sterile glass beads $(0.4-0.6 \mathrm{~mm} \varnothing)$, were added to $0.6 \mathrm{~mL}$ of concentrated cell suspension with $0.2 \mathrm{~mL}$ of $20 \%$ PEG (MW8000) and about $1 \mu \mathrm{g}$ of the desired plasmid (pSI106PLK-tpCRTIop). Negative controls, done in the same conditions with the empty plasmid (pSI106PLK), were included in all the transformation reactions. This mixture was agitated for 10s, resuspended in fresh TAP medium, and spread onto the selective solid medium with the indicated concentration of norflurazon. Transformed colonies were visible after 4 or 5 days.

\subsection{Determination of Carotenoids}

Samples from C. reinhardtii cultures, grown in TAP liquid medium supplemented with $1.5 \mu \mathrm{g}$ $\mathrm{mL}$ of norflurazon in the same conditions described in Section 3.1., were used for the extraction of carotenoids with methanol as described by Linchtehaler [42]. The chromatographic analysis was performed in a Merck Hitachi HPLC equipped with a diode array detector as described by Young and coworkers [28] using an RP-18 column, a flow rate of $1 \mathrm{~mL} \mathrm{~min}^{-1}$, and a final injection volume of $100 \mu \mathrm{L}$. Two mobile phases were used: Solvent A (ethyl acetate 100\%) and solvent B (acetonitrile: $\mathrm{H}_{2} \mathrm{O}$; 9:1 v/v). The gradients applied were: $0-16 \min 0-60 \% \mathrm{~A} ; 16-30 \mathrm{~min} 60 \% \mathrm{~A}$; and $30-35 \mathrm{~min} 100 \% \mathrm{~A}$. Standards were supplied by DHI (Hoersholm, Denmark). All experiments were done in triplicate, and the average values and standard deviation are represented. The significant differences have been analysed by a t-student test with a confidence level of $95 \%$.

\subsection{Dry Weight Determination}

Dry weight was determined by filtering an exact volume of microalgae culture $(30 \mathrm{~mL})$ on pre-tared glass-fiber filters (GF/F Whatman). The filter was washed with a solution of ammonium formate $(0.5 \mathrm{M})$ to remove salts and dried at $100{ }^{\circ} \mathrm{C}$ for $24 \mathrm{~h}$. The dried filters were weighed in 
an analytical balance and the dry weight calculated by the difference. Values are the average of three measurements.

\subsection{Herbicide Sensitivity Test}

Norflurazon sensitivity was assayed on multi-well plates with the corresponding agar-solidified medium supplemented with the indicated concentrations of the herbicide.

\section{Conclusions}

The use of a synthetic codon-adapted CRTIop gene fused to a chloroplastic transit peptide as a selectable marker for the genetic transformation of Chlamydomonas reinhardtii has been shown to be a reliable and efficient approach for the selection of transformants, contributing to increase the non-antibiotic-dependent markers available for microalgae and plant cells. C. reinhardtii transformants selected on norflurazon have been shown to have the CRTIop gene correctly inserted into their genomes to acquire a 33-fold increased resistance to norflurazon and be stable for long periods of time. This is a good alternative to genetic markers based on resistance to antibiotics, which can be very useful to establish genetic transformations systems for new microalgal species which are recalcitrant to inhibition with traditional antibiotics, as usually happens with marine and halophyllic microalgae. It can also be an interesting alternative for the selection of higher plants transformants without using antibiotics.

Supplementary Materials: The following are available online at http://www.mdpi.com/2218-1989/9/3/49/s1. Figure S1: Norflurazon sensitivity test for several microalgae species. Drops $(10 \mu \mathrm{L})$ of concentrated cultures of the microalgae Tetraselmis suecica, Dunaliella salina, Dunaliella bardawill and Chlorella sorokiniana were spotted on agar-solidified culture medium with increasing concentrations of the bleaching herbicide norflurazon (from 0 to 5 $\mu \mathrm{g} \mathrm{mL}^{-1}$ ) and their growth was evaluated 10 days after inoculation. The culture media used was that described in Materials and Methods for each species, excepting that the concentration of $\mathrm{NaCl}$ was reduced to half the salinity of the seawater for T. suecica and to $0.5 \mathrm{M}$ for D. salina and D. bardawill. Figure S2: Norflurazon sensitivity test for different Nor $^{\mathrm{R}}$-transformants of the microalga Chlamydomonas reinhardtii. Drops $(10 \mu \mathrm{L})$ of concentrated cultures of the transformants T1, T11 and T19 obtained as described in the legend of Figure 2, were spotted on agar-solidified TAP culture medium with increasing concentrations of the bleaching herbicide norflurazon (from 0 to $200 \mu \mathrm{g} \mathrm{mL}^{-1}$ ) and their growth was evaluated 10 days after inoculation. Figure S3: Chromatographic analysis of pigments extracts from control and $\mathrm{Norf}^{\mathrm{R}}$-Chlamydomonas transfomants grown in the presence of norflurazon $\left(1.5 \mu \mathrm{g} \mathrm{mL}^{-1}\right)$. Conditions for chromatographic separation are described in Materials and Methods. Peaks were identified as: neoxanthin/loroxanthin (1), violaxanthin (2), antheraxanthin (3), lutein (4), zeaxanthin (5), chlorophyll b (6), chlorophyll a (7) and $\beta$-carotene (8) and phytoene (9). Figure S4: Growth curves (A,B) and carotenoid content $(\mathrm{C}, \mathrm{D})$ of untransformed (Control) and transformed $\left(\mathrm{Norf}^{\mathrm{R}}\right)$ strains of Chlamydomonas reinhardtii cultured without and with increasing concentrations of the herbicide norflurazon. Cultures of the control untransformed cells and of the Norf ${ }^{R}$-transformant T21 were harvested at the beginning of exponential phase of growth and resuspended in fresh TAP medium without norflurazon or supplemented with 1.5, 8 and $20 \mu \mathrm{g} \mathrm{mL}^{-1}$ of norflurazon. Dry weight (DW) was determined every $24 \mathrm{~h}$. In addition, the carotenoid content of control and transformed $\left(\mathrm{Norf}^{\mathrm{R}}\right)$ cells grown for $24 \mathrm{~h}$ without or with $1.5 \mu \mathrm{g} \mathrm{mL}^{-1}$ of norflurazon were also determined. Neoxanthin and loroxanthin (Neo/Lor) are expressed a unique value since they are not resolved in the analytical conditions used. All the values are the average of three biological replicates and bars represent standard deviation.

Author Contributions: All authors have contributed to this research and agree to authorship, and submit this manuscript for its revision and publication. Conceptualization, R.L. and A.M.-M.; methodology, A.M.-M., A.B., and M.V.; software, A.M.-M.; investigation, A.M.-M. and A.B.; data curation, J.V. and M.V.; Writing-Original Draft preparation, R.L.; Writing-Review Andediting, A.M.-M., M.V., J.V., and R.L.; supervision, R.L. and J.V.; project administration, R.L. and J.V.; funding acquisition, R.L. and J.V.

Funding: This research was funded by the Spanish Agencia Estatal de Investigación [AGL2016-74866-C32R-AEI/FEDER] and the EU-INTERREG Program [INTERREG VA POCTEP-055 ALGARED_PLUS_5E].

Conflicts of Interest: The authors declare no conflict of interest. 


\section{References}

1. Varela, J.C.; Pereira, H.; Vila, M.; León, R. Production of carotenoids by microalgae: Achievements and challenges. Photosynth. Res. 2015, 125, 423-436. [CrossRef] [PubMed]

2. Valverde, F.; Romero-Campero, F.J.; León, R.; Guerrero, M.G.; Serrano, A. New challenges in microalgae biotechnology. Eur. J. Protistol. 2016, 55, 95-101. [CrossRef]

3. Khan, M.I.; Shin, J.H.; Kim, J.D. The promising future of microalgae: Current status, challenges, and optimization of a sustainable and renewable industry for biofuels, feed, and other products. Microb. Cell Factor. 2018, 17, 36. [CrossRef] [PubMed]

4. Schulze, P.S.C.; Guerra, R.; Pereira, H.; Schüler, L.M.; Varela, J.C.S. Flashing LEDs for Microalgal Production. Trends Biotechnol. 2017, 35, 1088-1101. [CrossRef] [PubMed]

5. Mallick, N.; Bagchi, S.K.; Koley, S.; Singh, A.K. Progress and Challenges in Microalgal Biodiesel Production. Front. Microbiol. 2016, 7, 1019. [CrossRef]

6. Rengel, R.; Smith, R.T.; Haslam, R.P.; Sayanova, O.; Vila, M.; León, R. Overexpression of acetyl-CoA synthetase (ACS) enhances the biosynthesis of neutral lipids and starch in the green microalga Chlamydomonas reinhardtii. Algal Res. 2018, 31, 183-193. [CrossRef]

7. Bellou, S.; Triantaphyllidou, I.-E.; Aggeli, D.; Elazzazy, A.M.; Baeshen, M.N.; Aggelis, G. Microbial oils as food additives: Recent approaches for improving microbial oil production and its polyunsaturated fatty acid content. Curr. Opin. Biotechnol. 2016, 37, 24-35. [CrossRef]

8. Gimpel, J.A.; Henríquez, V.; Mayfield, S.P. In Metabolic Engineering of Eukaryotic Microalgae: Potential and Challenges Come with Great Diversity. Front. Microbiol. 2015, 6, 1376. [CrossRef]

9. Scranton, M.A.; Ostrand, J.T.; Fields, F.J.; Mayfield, S.P. Chlamydomonas as a model for biofuels and bio-products production. Plant J. 2015, 82, 523-531. [CrossRef]

10. León, R.; Fernández, E. Nuclear Transformation of Eukaryotic Microalgae. In Transgenic Microalgae as Green Cell Factories; Springer: New York, NY, USA, 2007; Volume 616, pp. 1-11.

11. Nielsen, K.M.; Bøhn, T.; Townsend, J.P. Detecting rare gene transfer events in bacterial populations. Front. Microbiol. 2014, 4, 415. [CrossRef]

12. Brueggeman, A.J.; Kuehler, D.; Weeks, D.P. Evaluation of three herbicide resistance genes for use in genetic transformations and for potential crop protection in algae production. Plant Biotechnol. J. 2014, 12, 894-902. [CrossRef]

13. Kovar, J.L.; Zhang, J.; Funke, R.P.; Weeks, D.P. Molecular analysis of the acetolactate synthase gene of Chlamydomonas reinhardtii and development of a genetically engineered gene as a dominant selectable marker for genetic transformation. Plant J. 2002, 29, 109-117. [CrossRef]

14. Lapidot, M.; Raveh, D.; Sivan, A.; Arad, S.M.; Shapira, M. Stable chloroplast transformation of the unicellular red alga Porphyridium species. Plant Physiol. 2002, 129, 7-12. [CrossRef] [PubMed]

15. Grundman, O.; Khozin-Goldberg, I.; Raveh, D.; Cohen, Z.; Vyazmensky, M.; Boussiba, S.; Shapira, M. Cloning, mutagenesis, and characterization of the microalga Parietochloris incisa acetohydroxyacid synthase, and its possible use as an endogenous selection marker. Biotechnol. Bioeng. 2012, 109, 2340-2348. [CrossRef]

16. Michel, A.; Arias, R.S.; Scheffler, B.E.; Duke, S.O.; Netherland, M.; Dayan, F.E. Somatic mutation-mediated evolution of herbicide resistance in the nonindigenous invasive plant hydrilla (Hydrilla verticillata). Mol. Ecol. 2004, 13, 3229-3237. [CrossRef] [PubMed]

17. Arias, R.S.; Dayan, F.E.; Michel, A.; Howell, J.; Scheffler, B.E. Characterization of a higher plant herbicide-resistant phytoene desaturase and its use as a selectable marker. Plant Biotechnol. J. 2006, 4, 263-273. [CrossRef]

18. Breitenbach, J.; Zhu, C.; Sandmann, G. Bleaching Herbicide Norflurazon Inhibits Phytoene Desaturase by Competition with the Cofactors. J. Agric. Food Chem. 2001, 49, 5270-5272. [CrossRef] [PubMed]

19. Chamovitz, D.; Sandmann, G.; Hirschberg, J. Molecular and biochemical characterization of herbicide-resistant mutants of cyanobacteria reveals that phytoene desaturation is a rate-limiting step in carotenoid biosynthesis. J. Biol. Chem. 1993, 268, 17348-17353.

20. Cunningham, F.X.; Gantt, E. Genes And Enzymes of Carotenoid Biosynthesis in Plants. Annu. Rev. Plant Physiol. Plant Mol. Biol. 1998, 49, 557-583. [CrossRef]

21. Sandmann, G.; Römer, S.; Fraser, P.D. Understanding carotenoid metabolism as a necessity for genetic engineering of crop plants. Metab. Eng. 2006, 8, 291-302. [CrossRef] 
22. Misawa, N.; Nakagawa, M.; Kobayashi, K.; Yamano, S.; Izawa, Y.; Nakamura, K.; Harashima, K. Elucidation of the Erwinia uredovora carotenoid biosynthetic pathway by functional analysis of gene products expressed in Escherichia coli. J. Bacteriol. 1990, 172, 6704-6712. [CrossRef] [PubMed]

23. Misawa, N.; Yamano, S.; Linden, H.; de Felipe, M.R.; Lucas, M.; Ikenaga, H.; Sandmann, G. Functional expression of the Erwinia uredovora carotenoid biosynthesis gene crtl in transgenic plants showing an increase of beta-carotene biosynthesis activity and resistance to the bleaching herbicide norflurazon. Plant J. 1993, 4, 833-840. [CrossRef] [PubMed]

24. Paine, J.A.; Shipton, C.A.; Chaggar, S.; Howells, R.M.; Kennedy, M.J.; Vernon, G.; Wright, S.Y.; Hinchliffe, E.; Adams, J.L.; Silverstone, A.L.; et al. Improving the nutritional value of Golden Rice through increased pro-vitamin A content. Nat. Biotechnol. 2005, 23, 482-487. [CrossRef] [PubMed]

25. Fraser, P.D.; Romer, S.; Shipton, C.A.; Mills, P.B.; Kiano, J.W.; Misawa, N.; Drake, R.G.; Schuch, W.; Bramley, P.M. Evaluation of transgenic tomato plants expressing an additional phytoene synthase in a fruit-specific manner. Proc. Natl. Acad. Sci. USA 2002, 99, 1092-1097. [CrossRef] [PubMed]

26. Ducreux, L.J.M.; Morris, W.L.; Hedley, P.E.; Shepherd, T.; Davies, H.V.; Millam, S.; Taylor, M.A. Metabolic engineering of high carotenoid potato tubers containing enhanced levels of beta-carotene and lutein. J. Exp. Bot. 2005, 56, 81-89.

27. Díaz-Santos, E.; Vila, M.; Vigara, J.; León, R. A new approach to express transgenes in microalgae and its use to increase the flocculation ability of Chlamydomonas reinhardtii. J. Appl. Phycol. 2016, 28, 1611-1621. [CrossRef]

28. Suarez, J.V.; Banks, S.; Thomas, P.G.; Day, A. A new F131V mutation in Chlamydomonas phytoene desaturase locates a cluster of norflurazon resistance mutations near the FAD-binding site in 3D protein models. PLoS ONE 2014, 9, e99894. [CrossRef] [PubMed]

29. Steinbrenner, J.; Sandmann, G. Transformation of the green alga Haematococcus pluvialis with a phytoene desaturase for accelerated astaxanthin biosynthesis. Appl. Environ. Microbiol. 2006, 72, 7477-7484. [CrossRef]

30. Sharon-Gojman, R.; Maimon, E.; Leu, S.; Zarka, A.; Boussiba, S. Advanced methods for genetic engineering of Haematococcus pluvialis (Chlorophyceae, Volvocales). Algal Res. 2015, 10, 8-15. [CrossRef]

31. Huang, J.; Liu, J.; Li, Y.; Chen, F. Isolation and Characterization of the Phytoene Desaturase Gene As a Potential Selective Marker for Genetic Engineering of the Astaxanthin-Producing Green Alga Chlorella zofingiensis (Chlorophyta). J. Phycol. 2008, 44, 684-690. [CrossRef]

32. Xue, J.; Niu, Y.-F.; Huang, T.; Yang, W.-D.; Liu, J.-S.; Li, H.-Y. Genetic improvement of the microalga Phaeodactylum tricornutum for boosting neutral lipid accumulation. Metab. Eng. 2015, 27, 1-9. [CrossRef]

33. Prasad, B.; Vadakedath, N.; Jeong, H.-J.; General, T.; Cho, M.-G.; Lein, W. Agrobacterium tumefaciens-mediated genetic transformation of haptophytes (Isochrysis species). Appl. Microbiol. Biotechnol. 2014, 98, 8629-8639. [CrossRef] [PubMed]

34. Tran, P.T.; Sharifi, M.N.; Poddar, S.; Dent, R.M.; Niyogi, K.K. Intragenic Enhancers and Suppressors of Phytoene Desaturase Mutations in Chlamydomonas reinhardtii. PLoS ONE 2012, 7, e42196. [CrossRef] [PubMed]

35. Liu, J.; Sun, Z.; Gerken, H.; Huang, J.; Jiang, Y.; Chen, F. Genetic engineering of the green alga Chlorella zofingiensis: A modified norflurazon-resistant phytoene desaturase gene as a dominant selectable marker. Appl. Microbiol. Biotechnol. 2014, 98, 5069-5079. [CrossRef] [PubMed]

36. Loppes, R.; Radoux, M.; Ohresser, M.C.; Matagne, R.F. Transcriptional regulation of the Nia1 gene encoding nitrate reductase in Chlamydomonas reinhardtii: Effects of various environmental factors on the expression of a reporter gene under the control of the Nia1 promoter. Plant Mol. Biol. 1999, 41, 701-711. [CrossRef] [PubMed]

37. Guillard, R.R.; Ryther, J.H. Studies of marine planktonic diatoms. I. Cyclotella nana Hustedt, and Detonula confervacea (cleve) Gran. Can. J. Microbiol. 1962, 8, 229-239. [CrossRef] [PubMed]

38. Johnson, M.K.; Johnson, E.J.; MacElroy, R.D.; Speer, H.L.; Bruff, B.S. Effects of salts on the halophilic alga Dunaliella viridis. J. Bacteriol. 1968, 95, 1461-1468. [PubMed]

39. León, R.; Couso, I.; Fernández, E. Metabolic engineering of ketocarotenoids biosynthesis in the unicelullar microalga Chlamydomonas reinhardtii. J. Biotechnol. 2007, 130, 143-152. [CrossRef]

40. Sizova, I.; Fuhrmann, M.; Hegemann, P. A Streptomyces rimosus aphVIII gene coding for a new type phosphotransferase provides stable antibiotic resistance to Chlamydomonas reinhardtii. Gene 2001, 277, 221-229. [CrossRef] 
41. Kindle, K.L. High-frequency nuclear transformation of Chlamydomonas reinhardtii. Proc. Natl. Acad. Sci. USA 1990, 87, 1228-1232. [CrossRef]

42. Lichtenthaler, H.K. Chlorophylls and carotenoids: Pigments of photosynthetic biomembranes. Methods Enzymol. 1987, 148, 350-382.

(C) 2019 by the authors. Licensee MDPI, Basel, Switzerland. This article is an open access article distributed under the terms and conditions of the Creative Commons Attribution (CC BY) license (http://creativecommons.org/licenses/by/4.0/). 